\title{
The Relevance Of The Expiration-Effect Of Derivative Instruments From Ibex-35 Index On The Stock Market In Spain.
}

Lucy Amigo Dobaño, (E-mail: lamigo@uvigo.es), University of Vigo, Spain

\begin{abstract}
The importance of derivative financial instruments is reflected in the steady growth observed in their trading volumes at the worldwide level, from the moment they were first created at the end of the $20^{\text {th }}$ Century. In this framework, and considering the high grade of correlation among the different sectors of the asset market, we will analyze like it affects the expiration-effect of derivative instruments from the selective ibex-35 spanish index to the rest indexes of the market. To do so, we consider the different segments of the Spanish stock market, as represented by their general and sector indexes with daily data and we verify whether the stock market indexes show returns, volatility and trading volumes on the expiration dates of the derivatives that are significantly different from those observed on the rest of the days of the period. Our analyses indicate that the models of the expiration effect are indeed different among segments, verifying, in general, that this effect only appears in the volume and the returns. With such a focus, the investor could foresee an optimal strategy to make profits and minimize his risk on the stock prices
\end{abstract}

\section{Introduction}

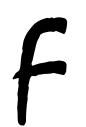

rom the moment they were created at the end of the $20^{\text {th }}$ Century, derivative financial products on assets of variable returns have become increasingly important. This fact is reflected in their trading volumes around the world. In such a framework, the close relationship that exists between the trading rate of the derivatives and the values of the underlying assets has given rise to abundant financial literature over the last couple of years, in an effort to discover if there really is an expiration effect on the underlying assets, as a result of the expiration dates of such derivative products, and which distorts their efficient trading and pricing on the market.

The financial literature is not at all conclusive with regard to the topic, as the results obtained vary somewhat, depending on the markets and the sample periods that are considered. Furthermore, the previous studies published are all based on the original paper of Cinar and $\mathrm{Vu}$ (1987), in which the expiration effect of the options on returns is analyzed, negative returns prior to the expiration date are explained by the sale of options and, on the other hand, high returns have been explained by the lack of liquidity to undo short positions. In Stoll and Whaley (1987), using data taken from the US market, it is shown that there is an expiration-day effect on returns and volume, its causes being blamed on arbitration operations.

On the other hand, in Edwards (1988), the expiration effect on volatility is analyzed, concluding that it does increase on the expiration date. In verify to this study, however, Grossman (1988) concludes that there is a decrease in volatility on the expiration date. In Browne, Fell and Hughes (1994), in an analysis of returns, a distorting effect is assumed to exist in both the increase and the decrease in the returns of the American markets and it is attributed to the arbitration operations that are carried out in the market.

Readers with comments or questions are encouraged to contact the author via email. 
For the Spanish stock market, there have been several studies aimed at analysing the expiration effect. Among them, we should mention Corredor, Lechón and Santamaría (1997) as precursors, who, in a study with daily data, confirm the importance of the expiration date on the volume, while in Brown (1998) such results are not detected, although a significant expiration effect is observed on the volume and the volatility with intra-daily data. Blanco (1998) analyzes the expiration effect on the volatility, obtaining results that confirm its existence, but only for certain assets on the Spanish market and, even so, it is not very significant. Finally, Andrés (2001), in an analysis of the expiration effect of derivative products from the Ibex 35 on the stocks included in the index during the period 1992-1998, and using daily data, concludes that on the expiration date, the trading volume increases significantly, the liquidity just slightly, and, in verify to these, neither the mean nor the volatility of the returns are affected by the expiration.

In summary then, many of the arguments put forward in these works are based on empirical studies, and focus mainly on the agents' interest in influencing the liquidating price. ${ }^{1}$ There are no theoretical models, however, to support any of the conclusions drawn.

This study is aimed at verifying whether an expiration effect actually exists in the Spanish stock market as a result of the expiration dates of the derivative products on the Ibex-35 index. We follow the methodology proposed by Andrés (2001), and focus on a combined study of both the futures and the options effects on the trading indexes of the Spanish Market, observing the fact that they both expire on the same day, (i.e., the third Friday of each month). With this sort of approach, the investor could arrive at an optimal strategy for making profits and minimizing risk on the in the Spanish Spot Market, based on a study of the historical series of returns and trading volumes.

The contribution that our analysis makes, in verify to the other studies previously mentioned, is two-fold. In the first place, it covers the study period of a recent sample and is characterized by very diverse economic circumstances and institutional settings, which brought on the beginning of a period of uncertainty in stock markets around the world, beginning with the events of September $11^{\text {th }} 2001$ in the United States, and aggravated by Argentina's economic crisis which began at the end of the same year. It will probably allow us to find some form of behavioural models in the stock market, particularly those that underlie periods of high volatility. Secondly, as a further contribution, we offer a more complete analysis than is presented in the existing literature, as we consider all of the segments of the Spanish stock market with variable returns. Our study, therefore, also includes, among others, the recently created Ibex NM index, which gives company values together with high growth potentials for technological sectors, quite similar to the style of the North American NASDAQ.

The combined result our work demonstrates that an expiration effect does exist, which is economically and statistically significant for normal levels of significance, on the volume of the different segments of the stock market and also on the mean returns. In verify, for none of the stock market indexes is there any evidence of an expiration effect on the volatility of the returns.

To achieve our aims, the study is structured as follows: Section 2 presents the theoretical framework of derivative financial instruments. In Section 3, a synthetic presentation is made of the data used and some of its basic characteristics during the sample period are explained. In Section 4, the existence of an expiration effect is verified on the volume, the mean and the conditional variance of the returns of the stock market indexes considered. Finally, in Section 5, our main conclusions are presented.

\section{Derivatives Financial Instruments: Theoretical Framework}

The derivatives instruments are one of the most sophisticated ways fixed-term contracting whose very essence and justification is in the need to efficiently administer the risks associated with economic uncertainty.

\footnotetext{
${ }^{1}$ It should also be interesting to do the empirical analysis in the opposite direction, to see whether the variations in the stocks markets (spot) could influence the variations in the trading price of the derivatives.
} 
Beginning with the initial development of the futures and financial options markets in the US, specifically in the city of Chicago, during the 1970's, now, a decade later, they have been included in most of the countries that have well-developed financial markets. In Europe, they were created gradually, starting with the EOE (European Options Exchange) in Holland, in 1978, the LIFFE (London International Financial Futures Exchange) in the UK, also in 1978, the MATIF (Marché a Terme International de France) in France, in 1985, the SOFFEX (Swiss Financial Futures Exchange) in Switzerland, in 1988, and the DTB (Deutsche Terminbourse) in Germany, in 1990, among others. In Spain, the Futures and Options Market was created in 1991, and was structured through the "MEFF, Sociedad Holding de Productos Derivados Financieros S.A.", ${ }^{2}$ with work centres in Madrid for stocks of variable returns, and in Barcelona for fixed returns.

Outside the European scene, other countries like Japan, Canada, Brazil, Singapore, Hong Kong and Australia have also organized markets for derivative instruments.

At the worldwide level, an outstanding aspect in the evolution of the derivatives markets is their steady growth, reflected in their ever-increasing trading volumes. In the case of Spain, the evolution of derivatives of variable returns was quite spectacular, with derivatives on the Ibex 35, for example, reaching figures of over $50 \%$ of the effective trading registered on the continuous market, after just one year of their appearance, and they have continued growing to reach an average of $200 \%$ of the underlying assets. This fact, together with the investors' interest in devising good strategies for reaping profits and minimizing risks, has encouraged us to analyze, empirically, how the expiration dates of futures and options on the selective Ibex-35 index affect spot price trading in the different segments of the Spanish stock market.

In this regard, it should be pointed out that our study only considers the Spanish derivatives market on indexes, which appeared in 1992, when Future Ibex 35 and Options Ibex 35 began operating and continued until September of 2001, when the Mini Futures and Options contracts began trading on the Ibex 35. An alternative model for covering and speculating on underlying assets of variable returns is options and futures contracts on certain stocks, although with a much lower volume than that traded in derivatives on the indexes, which is why we have not taken them into consideration in this analysis. We should also point out that our analyses focus on verifying the combined expiration effects of options and futures on the indexes, as they both expire on the same day, i.e., the third Friday of each month, except for public holidays, when they do so on the Thursday before. In spite of this, however, it is important to note that futures contracts are traded far more than options. ${ }^{3}$

\section{Empirical Regularities In The Behaviour Of The Spanish Stock Market}

The database used consists of daily data from the Spanish stock market. Specifically, we have access to the index series of Sociedad de Bolsas, S.A., Table 1. The sample period runs from the $7^{\text {th }}$ of April 2000 to the $28^{\text {th }}$ of December 2001 (432 observations).

Table 1

\begin{tabular}{|l|}
\hline Stock Market Indexes included in the sample \\
\hline Ibex 35 index (Ibex35) \\
\hline Ibex COMPLEMENTARIO index (IbexCOM) \\
\hline Ibex FINANCIERO index (IbexFIN) \\
\hline Ibex UTILITIES index (IbexUTI) \\
\hline Ibex INDUSTRIA Y VARIOS index (IbexIND) \\
\hline Ibex NUEVO MERCADO index (IbexNM) \\
\hline
\end{tabular}

\footnotetext{
${ }^{2}$ It has been an Official Market since July 1992, controlled and supervised by the CNMV (Comisión Nacional del Mercado de Valores). By Order of 8 July 1992.

${ }^{3}$ As an interesting reflection, we should mention that in 2001, approximately $88.76 \%$ of the derivatives on the Ibex 35 and traded on the MEFF were futures contracts, while only $11.24 \%$ were options. In this regard, we should point out a couple important peculiarities about the futures on indexes that make them different from the other futures markets. First, the underlying stock does not trade on the market and, therefore, to carry out arbitration operations the individual stocks have to be bought or sold in the same proportions as they appear in the index to be able to reply it. Secondly, liquidation is done by difference, which jeans that the arbitrators have to undo their positions in the stock market on the expiration day.
} 
The Ibex 35 index is composed of the 35 stocks most traded on the Market Inter-connection System of the four largest Spanish spot markets, and it is generally used as a reference index for the Spanish market. To be able to follow the behaviour of the other stocks that have traded, the Complementary Ibex index is calculated, which is composed of stocks which, although they are included in the sector indexes of the "Sociedad de Bolsas", are not included in the IBEX35 index.

Regarding the sector indexes, the IbexFIN index is composed of stocks included in the financial setting, such as banks and insurance companies that trade in the System of Market Interconnection of the four Spanish markets that have the largest trading volumes in Euros during the observation period. As for the Ibex Utilities index, this is composed of the stocks included in the services companies sector, whose prices, in opinion of the "Technical Assessors Committee", are subjected to a regime of controlled rates, which trade on the Market Inter-connection System of the four Spanish markets, and which have had the largest trading volumes in Euros during the observation period. The IbexIND index it is composed of the stocks included in the industrial sector and of several services that trade on the Market Inter-connection System of the four Spanish markets that have the largest trading volumes in Euros during the observation period. Finally, the IbexNM which is used specifically for the trading of stocks issued by companies who operate in technologically innovative sectors and whose business activities could be included in what is known as the New Economy.

Based on these series of data, the returns series are generated by means of logarithmic differences:

$$
R_{t}=100 * \log \left(p_{t} / p_{t-1}\right)
$$

where $p_{t}$ and $p_{t-1}$ are the values of the index at moments $t$ and $t-1$, respectively, and $R_{t}$ is the increment relevant to day $t .{ }^{4}$

The initial approach to verifying the possible expiration effect in the Spanish stock market, caused by the expiration dates of products derived from the indexes, is based on the descriptive statistics of the indexes of the different segments, analyzing the evolution of the returns and the volume, analogously, during the sample period (Table 1 of the Appendix) and secondly, differentiating among the expiration dates of the derived contracts and the rest of the days (Tables 2 and 3, respectively). Graph 1 shows the evolution of the indexes considered.

Graph 1: Temporal Evolution Of The Indixes

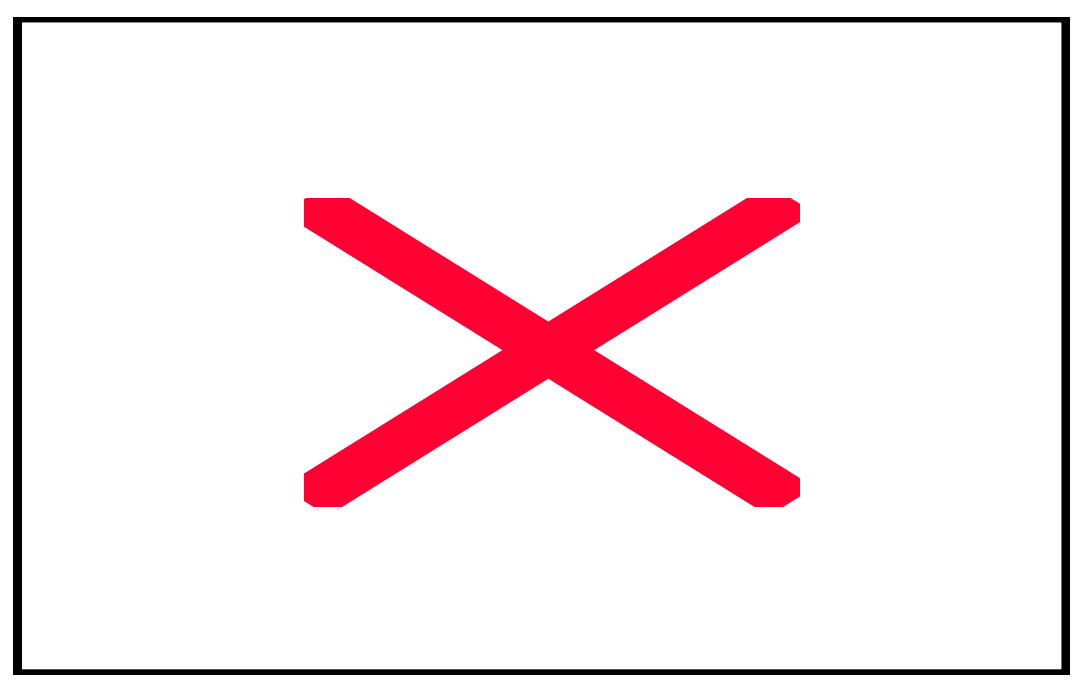

${ }^{4}$ The series considered here were defined in terms of neperian logarithms to establish their variances, considering the fact that they are non-negative but very volatile. For an overview, see Tauchen et al. (1996). 
Among the empirical regularities reflected in the returns, we observe, as is common in most financial series, that the average is approximately equal to zero, although in our case, the mean returns are always negative. This is logical, considering the circumstances inherent in the sample period considered and which describe an unfavourable market climate or "Bear Market", starting mainly from the events of September $11^{\text {th }} 2001$ in the United States and aggravated by the Argentinean crisis which began at the end of the same year.

When the indexes are analyzed individually for the entire sample, we observe that the greatest revaluation was obtained by the Ibex Financial index, which has the greatest increase in its returns $(9.41 \%)$, followed by the IbexNM $(8.42 \%)$, with the other indexes running between the $3.5 \%$ and $5.7 \%$. On the other hand, the most significant losses are seen in the IbexNM index (14.90\%), followed by the IbexFIN index (8.09\%), oscillating between a $4.54 \%$ and $6.76 \%$. The first observation that is extracted from these results, therefore, is that there is the greatest volatility in the stocks of the financial and technological sectors.

This implies that the IbexFIN index and IbexNM showed the greatest typical deviation in returns, especially the latter (3.02\%), which had its highest volatility ever. For the rest of indexes, the typical deviation reached values of between $0.91 \%$ and $1.85 \%$. In any event, although the typical deviation is one of the measurements of variability most commonly used in the literature, this is no more than a sample measure of the dispersion of a random variable from which no type of structure is determined, either for the evolution of the returns series or for the volatility.

We must also point out that, from the analysis of the distribution of the returns series, practically all the indexes show a bias to the left, especially the IbexCOM and IbexNM, showing their clear tendency towards negative returns. As such, it is possible that there is some sort of relationship between the liquidities of these indexes, because, IbexCOM and IbexNM are the ones with the smallest trading volumes. They represent a volume of just $3.54 \%$ and $8,33 \%$ of the index with the highest liquidity, the Ibex35.

The analysis of trading volumes in the different segments of the stock market shows, as was to be expected, that the highest increases and the greatest decreases have also occurred in the Ibex35, which implies that it is the market segment with the greatest variability in trading volumes, as a result of its broader base of stocks and its greater liquidity. This is the opposite of what happens with the indexes with the less liquid stocks, as in the case of the IbexNM and IbexCOM indexes, whose trading peaks were much lower than those of the others, especially those of the Ibex 35 .

On analyzing the empirical regularities of the returns and volumes series separately for expiration and nonexpiration dates, we observe that average returns are lower on expiration days but volatility is higher. This is reflected in the greater typical deviations, which are due precisely to the fact that on these days we see the highest increases as well as the biggest losses. From our analyses we also deduced that trading volumes increase significantly on the of non-expiration days and, inversely, the greatest falls in the trading take place on the expiration days, except in the case of the IbexCOM index. Therefore, there is more variability in trading volumes on the expiration dates, in general, with the exception of the IbexFIN and IbexUTI indexes. Such behaviour may well be due to the fact that the most traded stocks are the ones on the Ibex35 index, which serves as an underlying value for most of the contracts.

As such, and as a conclusion to this preliminary analysis through descriptive statistics, we can state that the Spanish stock market, represented through their many general and sector indexes, might well be affected by the expiration dates of financial derivative products from the selective Ibex-35 index.

\section{Options And Futures Expiration Effects From The Ibex-35 Index On The Stock Market}

In order to verify the possible expiration effect from Ibex-35 index on the stock market in Spain, we shall first verify whether the returns, volatility and trading volumes of the stock market indexes are significantly different on the expiration dates of the derivatives to those on the other days. To do so, our first analysis is based on the 
regression technique, to verify the possible existence of daily seasonality in the sample. We then model the series, incorporating variables that reflect the expiration effect and observing their levels of significance.

We first model the volume, also defined in neperian logarithms to stabilize their variance. The basic model we propose for verifying the presence of daily seasonality on the volume is given by the following expression:

$$
V_{t}=\beta_{0}+\beta_{1} D_{L}+\beta_{2} D_{M}+\beta_{3} D_{M I}+\beta_{4} D_{V}+\varepsilon_{t}
$$

where $\mathrm{Vt}$ is the neperian logarithm of the volume and $\mathrm{D}_{\mathrm{L}}, \mathrm{D}_{\mathrm{M}}, \mathrm{D}_{\mathrm{MI}}$, and $\mathrm{D}_{\mathrm{V}}$ are dummy variables that have a value of 1 on Mondays, Tuesdays, Wednesdays, and Fridays and zero on other days. The error term is reflected in et. In our first approach, the OLS (Ordinary Least squares) estimate of the model was done, from which we observed that, for the entire group of indexes, the trading volume on Tuesdays, Wednesdays and Fridays it is not significantly different from that on Thursdays, although on Mondays it is lower. The same results hold for all of the indexes separately, except for the IbexCOM, where a greater trading volume is seen on Fridays. These are just the preliminary results, but they are well supported by the literature on the topic. Peiró (1994), for example, finds less activity on Mondays, and Rystrom and Benson (1989) find less trading on Mondays and more on Fridays. Andrés (2001) also finds weekly seasonality around the weekend but the study focuses on very select indexes, like the Ibex 35 .

Considering only the variables that were significant in the modelling of the volume, and following the example of Andrés (2001), we now include three dummy variables to analyze what happens, not only on the expiration days, but also on next days around them. To do so, we include the three variables, $D_{t}$ which has a value of 1 on the expiration days and zero on all the other days, $D_{t-1}$ which has a value of 1 on the day before the expiration and zero on the other days, $D_{t-2}$ which has a value of 1 two days before the expiration and zero otherwise, and $D_{t+1}$ which has a value of 1 one on the day after the expiration and zero otherwise. The argument behind this is that it seems logical that the expiration effect should spill over and not be all concentrated on the actual day. Furthermore, it is natural to expect a dwindling of the effect on the days following the expiration. As such, our model is expressed as follows:

$$
V_{t}=\beta_{0}+\beta_{1} D_{L}+\beta_{4} D_{V}+\sum_{j=-2}^{j=1} \delta_{j} D_{t+j}+\varepsilon_{t}
$$

The results of the OLS estimate, robust to heteroskedasticity and auto-correlation (Newey-West, 1987), are presented in Table 4 of the Appendix. The analysis of these results reveals the existence of a statistically significant positive effect on the trading volume on the expiration day on most of the indexes, except for the IbexCOM and the IbexNM. We also verify, for the entire group of the indexes except the IbexCOM and the IbexNM, a highly significant effect on the day after the expiration. This could be due to the increase in operations on the stock market on these days, and especially so for stocks from the most liquid segments of the stock market. In other words, it is possible that the absence of an expiration effect in the IbexCOM and IbexNM indexes could be because the smaller capitalization of their stocks and, thus, they tend to be less used in speculation operations on the expiration days. On the contrary, our analyses show no increase in the volume on the days before the expiration, except for the Ibex 35 and IbexUTI where a significant increase is seen on the two days before the expiration.

The analysis of the possible impact of the expiration effect on the average returns is done with a procedure that is quite similar to the one used for the volume. We first verify the possible existence of daily seasonality in the series, and then include the four dummy variables we created to measure the significance of the expiration effect. As such, the final model to be estimated is given in the following expression:

$$
R_{t}=\beta_{0}+\beta_{3} D_{M I}+\beta_{4} D_{V}+\sum_{j=-2}^{j=1} \delta_{j} D_{t+j}+\varepsilon_{t}
$$


where Rt represents the returns. The results of the estimate for OLS robust to heteroskedasticity and auto-correlation are shown in Table 5 of the Appendix. It should be noted that the estimates confirm the absence of weekly seasonality in the series of the average returns for the entire group of indexes. These results support other empirical studies on this aspect, such as León and Mora (1996). Our analyses demonstrate the existence of a significant effect on the average returns on the indexes on the day of expiration, except for the IbexCOM. To be more specific, the analysis shows that the market returns are smaller on the expiration dates of derivatives. These results differ somewhat from those previously published the literature, which generally finds no significant effect on the returns, (among others, Brown, 1998), op cit. This author, in fact, finds a fall in the returns of the index on the day after the expiration of the derivatives, which is logical if we consider the great pressure exerted on the prices by the intense sales. This may be due to fact that the greatest volume we observed before was in sales of stocks, which always causes decrease in the trading price.

To guarantee the suppositions implicit in the estimation method employed for the volume and the returns, we tested for normality, non-auto-correlation and non-heteroskedasticity in the residuals of the models, which allowed us to verify the results we obtained. However, for the model that verifies the expiration effect on returns, although it indicates, in general, an absence of auto-correlation in the residuals, there is, in fact, evidence of autocorrelation in the squared residuals. These values are reflected in the Ljung-Box statistic and the ARCH test in Table 5 of the Appendix. In this respect, since the squared residuals of the yields continue to have a structure, we shall now model the conditional variance of the yield. ${ }^{5}$

In accordance with the above, and basing ourselves on the paper of Engle (1982), we develop different autoregressive conditional heteroskedasticity models to try and explain the dynamic behaviour of the volatility, the aim being to arrive at a model for the volatility, rather than the actual measurement of the volatility. The ARCH(q) model proposed by Engle (1982) supposes that the variance of the disturbance changes with time, so that the conditional variance is a lineal function of the last errors squared. As such, if the past errors are large, the variance will also be. The ARCH model is, undoubtedly, the one that has been employed most in modelling the volatility of financial series, and it has attracted great attention in the Econometrics literature over the last decade, in both Theoretical and the Applied Econometrics. ${ }^{6}$

The basic formula for this model is to consider a series $y_{t}$ (from $t=1$ to $t=T$ ), as a sequence of random variables, $\varepsilon_{t}$, independent and identically distributed, and with a unitary/single/unique variance, multiplied by a factor $\sigma_{t}$, denominated volatility. ${ }^{7}$ In other words:

$$
y_{t}=\varepsilon_{t} \sigma_{t} ; \quad \varepsilon_{t} \operatorname{IIN}(0,1)
$$

where the time changes in the conditional variance $\sigma_{t}^{2}=\operatorname{Var}\left(y_{t} / \Psi_{t-1}\right.$, ) is to be modelled as a function of the past observations of the series, through the following linear function:

$$
\sigma_{t}^{2}=\alpha_{0}+\sum_{i=1}^{q} \alpha_{i} \varepsilon_{t-i}^{2}=\alpha_{0}+\alpha(L) \varepsilon_{t-1}^{2}
$$

\footnotetext{
${ }^{5}$ It is crucial to remember that if we ignore the presence of conditional heteroskedasticity in the yields leads to a loss of efficiency in the estimation of the parameters of the model and can even cause the estimates of the Standard errors of the parameters to be inconsistent.

${ }^{6}$ For a more thorough theoretical analyses of this sort of modelling, see the original article by Engle (1982). Also, Nelson (1994), provide a detailed theoretical analysis.The ARCH models have undergone several reforms, in accordance with the empirical regularities of the series, which are, among others, an excess of kurtosis, great variations generally followed by important changes and small variations followed by small changes, a leverage effect, etc.

${ }^{7}$ The volatility is a positive function which is variable in time and measurable with respect to $\Psi_{\mathrm{t}-1}=6 \mathrm{y}_{1}, \ldots, \mathrm{y}_{\mathrm{t} 1}>$, set of information immediately available $t-1$.
} 
$\mathrm{L}$ being the lag operator and $q$ the order of the ARCH process.

In our study, and following the example of León and Mora (1996), we propose to model the variance with a GARCH(1,1) model developed by Bollerslev (1986). As such, the model to be estimated will be as follows:

$$
\sigma_{t}^{2}=\alpha_{0}+\alpha_{1} \varepsilon_{t-1}^{2}+\alpha_{2} \sigma_{t-1}^{2}
$$

However, as we already know that the impacts on the volatility may well be non-symmetrical, as Christie (1982) among others have demonstrated, it seems appropriate to use a model that reflects such a possibility, (i.e., the so-called leverage effect). From the different options that the literature offers for this model, we have opted for the GJR, proposed by Glosten, Jaganathan and Runkle (1993).

The formal expression of the conditional variance GJR(1,1) is as follows:

where St - is a dummy variable that has a value of 1 when the shocks or unforeseen component $\left(\varepsilon_{t}\right)$ have a negative

$$
\sigma_{t}^{2}=\alpha_{0}+\alpha_{1} \varepsilon_{t-1}^{2}+\alpha_{2} \sigma_{t-1}^{2}+\alpha_{3} \varepsilon_{t-1}^{2} S_{t-1}^{-}
$$

sign and 0 otherwise. The impact of the news, or shocks from the rate of returns of the Indexes on the volatility, will depend on the sign of the parameter estimated for this dummy variable. In any case, this model, which allows a different response from the volatility to the shocks, whether positive or negative, maintains the supposition that a minimum of volatility is obtained in the absence of unexpected reports.

Our next step is to observe the impact of the expiration effect on the variance of the returns. To do so, dummy variables that reflect daily seasonality in the variance equation are included in the GARCH and GJR models. The results indicate that none of these variables are statistically significant. We then include the variables created to analyze the expiration effect on different days in the models. As such, Equations [9] and [10] represent the final expressions of the GARCH and GJR models, respectively:

$$
\sigma_{t}^{2}=\alpha_{0}+\alpha_{1} \varepsilon_{t-1}^{2}+\alpha_{2} \sigma_{t-1}^{2}+\sum_{j=-2}^{j=1} \delta_{j} D_{t+j}+\varepsilon_{t}
$$

and,

$$
\sigma_{t}^{2}=\alpha_{0}+\alpha_{1} \varepsilon_{t-1}^{2}+\alpha_{2} \sigma_{t-1}^{2}+\alpha_{3} \varepsilon_{t-1}^{2} S_{t-1}^{-}+\sum_{j=-2}^{j=1} \delta_{j} D_{t+j}+\varepsilon_{t}
$$

The results of the estimate for maximum likelihood of the $\operatorname{GARCH}(1,1)$ models and the $\operatorname{GJR}(1,1)$ are, in general, quite similar. As such, in an effort to facilitate the presentation and interpretation of the results, in the Table 6 of the Appendix we present the estimates from the GJR model when the parameter of asymmetry is statistically significant and the logarithm of the function of likelihood is greater or very close to that of the GARCH. As another case, the estimates derived from the GARCH modelling of the variance are presented. The comparation among the different models was also done according to SIC (Schwarz Information Criterion) and AIC (Akaike Information Criterion). ${ }^{8}$

8 In this regard, it should be remembered the SIC is defined as $\operatorname{SIC}=2 \operatorname{Ln}\left(L_{m v}\right)-q \operatorname{Ln}(T)$, where $L_{m v}$ is the function of maximum likelihood of the model evaluated with parameters estimated, $q$ is the number of parameters in the model, and $T$ is the number of observations. In accordance with this criterion, the model with the higher SIC is preferable. The AIC criterion, is defined as $A I C=T L n\left(\sigma^{2}\right)+T+2 q$, where $\sigma^{2}$ is the maximum 
The results of this estimation, which are quite in line with those already published in the literature, show that none of the variables considered for verifying the expiration effect were statistically significant, and they show no significant effect on the conditional variance of the returns on the expiration date.

There are other important conclusions to be drawn from this analysis. The estimate of the auto-regressive effect for the entire group of the indexes is remarkable accurate, which suggests great inertia in the volatility. We should also point out that although the impact of a news item on the volatility, independently of its sign, is always positive, in our analyses the positive sign seems to indicate that negative values of the unexpected news cause greater increases in the volatility than its positive values of the same size and, thus, the risk increases more when the actual returns are smaller than the expected ones. A final comment on this Table, which we also consider relevant, is that we have verified that there is seasonality in all of the indexes $\left(\alpha_{1}+\alpha_{2}<1\right)$ although it is almost non-existent, indicating permanent shocks in the volatility, especially in the case of the IbexFIN, the IbexIND and the IbexNM. In all of the cases, however, we verified the robustness of the results of our study.

In synthesis then, as we see it, the investor who bases his strategy on the history of returns and trading volumes of the series, would have a adequate analytical tool, not only for operations on the spot markets, but for the managing of medium and long-term risk portfolios as well.

\section{Conclusions}

This study was intended to verify whether an expiration effect from the expiration dates of financial derivatives on the Ibex-35 index exists in the Spanish stock market. To do so, we considered all segments of the stock market, using a sample of daily data that reflects their recent evolution. This sort of analysis is particularly relevant because the investor who bases his strategy on a study of the recent historical series of returns and trading volumes, could arrive at an optimal strategy for making profits and keeping his risk to a minimum on the Spanish spot market.

By analyzing the most important descriptive statistics of the series of returns and trading volumes for expiration and non-expiration days separately, it seems clear that, in general, lower mean returns are observed on the expiration dates, together with higher volatility in the returns of the underlying stocks, caused by considerable rises and falls in the trading rates on such days and, finally, a higher trading volume in general than on the other nonexpiration days.

Our approach to verifying the possible existence of an expiration effect in the Spanish stock market proposes an analysis based on the regression technique and testing for daily seasonality in the sample. The analysis is subsequently enlarged by including dummy variables that could reflect the possible expiration effect. After estimating these models, we have obtained some very interest results and arrived at important conclusions.

The first important fact is the existence of a statistically significant positive effect on the trading volume on the expiration day, and a highly significant effect on the following day, for most of the indexes. The exception constitutes it the IbexCOM and IbexNM, which is most likely due to the smaller capitalization of the stocks on these indexes and to the fact that they are less used in arbitration operations on the expiration days. On the other hand, our analyses find no increase in the trading volume on the days before the expiration, except in the cases of the Ibex 35 and the IbexUTI, where it is statistically significant on the two days before the expiration date.

Secondly, our results show the existence of a significant effect on the average returns of the indexes on the expiration day, except in the case of the IbexCOM. In particular, the analysis shows that the returns are smaller on the expiration days. These results do not agree with the ones previously published in the literature on the matter, which find no significant effect on the returns in general, (Pardo (1998), among others). On the contrary, Pardo finds a fall in the

likelihood estimator of the variance, $q$ is the number of parameters in the sample and $T$ is the number of observations. In accordance with this criterion, the model with the lowest value is chosen. 
returns of the index on the day after the expiration of the derivatives, which is quite logical, considering the great pressure exerted on the prices by the higher sales. Our results show that for the rest of the days around the expiration date there is no statistically significant effect in any of the cases, neither on the days before nor on the day after the expiration. Given the loss of efficiency in the parameters estimated from the returns of the different indexes, due to the presence of a structure in the squared residuals of such estimates of the returns, we eventually finished our analyses by modelling the conditional variance of the returns for each case separately. To do so, we employed an alternative method which was commonly used during the 1980's in the modelling of financial series. The results do not indicate the existence of any significant effect on the variance of the different indexes as a result of the expiration of derivatives. These results are quite in line with those already published the empirical literature on the topic, although such analyses focused exclusively on the Ibex35 and on older sample data.

In summary, our empirical analyses indicate that the expiration of financial derivatives of variable yield, does affect the stock market, represented by different trading segments. It particularly affects the trading volume and the average returns, although it has no significant influence on the volatility. The effect on these two variables has been verified on the expiration day, and only in the case of the volume do we also observe a significant effect that continues onto the day after, although this is only so for very few indexes. We could not conclude our work without expressing the need for similar analyses of stock markets in other economies, which would afford better comparisons in keeping with our own narrow market.

Although this study describes certain behavioural patterns in the derivatives markets that affect the stock market, we should not forget that, as in any other financial decision, the most advisable approach for an investor on the stock market, whether he is hedging or speculating, is to accurately weight the aspects of security, risk and returns on the operation. 


\section{APPENDIX}

TABLE 1. EMPIRICAL REGULARITIES OF THE SERIES (431 observations)

\begin{tabular}{|c|c|c|c|c|c|c|c|c|c|c|c|c|}
\hline & \multicolumn{2}{|c|}{ Ibex35 } & \multicolumn{2}{|c|}{ IbexCOM } & \multicolumn{2}{|c|}{ IbexFIN } & \multicolumn{2}{|c|}{ IbexUTI } & \multicolumn{2}{|c|}{ IbexIND } & \multicolumn{2}{|c|}{ IbexNM } \\
\hline & Return & Volume & Return & Volume & Return & Volume & Return & Volume & Return & Volume & Return & Volume \\
\hline Mean & -0.0787 & 1.68. $10^{9}$ & -0.0336 & $5.94 .10^{7}$ & -0.0327 & $4.82 .10^{8}$ & -0.0818 & $8.09 .10^{8}$ & -0.0469 & $3.12 .10^{8}$ & -0.3113 & $1.40 .10^{8}$ \\
\hline Maximum & 5.7890 & $5.13 .10^{9}$ & 3.5854 & $1.22 .10^{9}$ & 9.4190 & $4.27 .10^{8}$ & 5.1100 & $2.36 .10^{9}$ & 4.4278 & 1.48. $10^{9}$ & 8.4230 & $1.00 .10^{8}$ \\
\hline Minimum & -5.9931 & $6.81 .10^{8}$ & -6.7659 & 7906942 & -8.0967 & $1.28 .10^{8}$ & -5.2090 & $2.65 .10^{8}$ & -4.5407 & 83752623 & -14.9900 & 24161513 \\
\hline Std.dev & 1.6552 & $5.28 .10^{8}$ & 0.9160 & 82667283 & 1.9433 & $3.32 .10^{8}$ & 1.8556 & $2.78 .10^{8}$ & 1.0578 & $1.41 .10^{8}$ & 3.0258 & $1.08 .10^{8}$ \\
\hline Skewness & -0.0658 & 1.9418 & -1.1317 & 8.819 & -0.0976 & 5.911 & 0.0040 & 1.488 & -0.2291 & 3.587 & -0.5252 & 3.149 \\
\hline
\end{tabular}

TABLE 2. EMPIRICAL REGULARITIES OF THE SERIES (Expiration-day of index futures and options , 21 observations)

\begin{tabular}{|c|c|c|c|c|c|c|c|c|c|c|c|c|}
\hline & \multicolumn{2}{|c|}{ Ibex35 } & \multicolumn{2}{|c|}{ IbexCOM } & \multicolumn{2}{|c|}{ IbexFIN } & \multicolumn{2}{|c|}{ IbexUTI } & \multicolumn{2}{|c|}{ IbexIND } & \multicolumn{2}{|c|}{ IbexNM } \\
\hline & Return & Volume & Return & Volume & Return & Volume & Return & Volume & Return & Volume & Return & Volume \\
\hline Mean & -6.4302 & 35497.39 & -2.2305 & 35636.85 & -0.7579 & $6.9 .10^{8}$ & -1.6245 & $1.07 .10^{9}$ & -1.0968 & 3.87. $10^{8}$ & -6.253 & $1.65 .10^{8}$ \\
\hline Махітит & 0.0953 & 37246 & 0.0953 & 37246 & 23.1316 & 1.27. $10^{9}$ & 15.031 & $2.21 .10^{9}$ & 13.152 & 7.62. $10^{8}$ & 28.379 & $4.65 .10^{8}$ \\
\hline Minimum & -130.17 & 6370.10 & -46.182 & 9298.90 & -32.401 & $3.01 .10^{8}$ & -13.006 & 4.57. $10^{8}$ & -24.396 & 1.97. $10^{8}$ & -48.879 & 56602723 \\
\hline Std.dev & 29.126 & 6676.21 & 10.345 & 6037.34 & 11.109 & $2.89 .10^{8}$ & 7.627 & $3.98 .10^{8}$ & 7.521 & 1.34. $10^{8}$ & 18.230 & $1.21 .10^{8}$ \\
\hline Skewness & -4.024 & -4.141 & -4.024 & -4.140 & -0.582 & 0.763 & 0.464 & 0.888 & -1.203 & 0.981 & -0.332 & 1.210 \\
\hline
\end{tabular}

TABLE 3. EMPIRICAL REGULARITIES OF THE SERIES (Non Expiration-day of index futures and options, 410 observations)

\begin{tabular}{|c|c|c|c|c|c|c|c|c|c|c|c|c|}
\hline & \multicolumn{2}{|c|}{ Ibex35 } & \multicolumn{2}{|c|}{ IbexCOM } & \multicolumn{2}{|c|}{ IbexFIN } & \multicolumn{2}{|c|}{ IbexUTI } & \multicolumn{2}{|c|}{ IbexIND } & \multicolumn{2}{|c|}{ IbexNM } \\
\hline & Return & Volume & Return & Volume & Return & Volume & Return & Volume & Return & Volume & Return & Volume \\
\hline Médium & -0.308 & 36864.54 & -0.101 & 36873.23 & -0.036 & $4.71 .10^{8}$ & -0.086 & $7.95 .10^{8}$ & -0.047 & $3.08 .10^{8}$ & -0.323 & 1.39. $10^{8}$ \\
\hline Махітит & 0.018 & 37253 & 0.018 & 37253 & 5.784 & $4.27 .10^{9}$ & 5.110 & $2.36 .10^{9}$ & 3.018 & $1.48 .10^{9}$ & 9.423 & $1.00 .10^{9}$ \\
\hline Minimum & -127.71 & 6265.70 & -43.038 & 9827.80 & -8.096 & $1.28 .10^{8}$ & -7.073 & $2.65 .10^{8}$ & -4.199 & 83752623 & -14.990 & 24161513 \\
\hline Std.dev & 6.315 & 1525.45 & 2.128 & 1351.01 & 1.953 & $3.31 .10^{8}$ & 1.948 & $2.64 .10^{8}$ & 1.053 & 1.40. $10^{8}$ & 3.158 & $1.08 .10^{8}$ \\
\hline Skewness & -20.124 & -19.727 & -20.124 & -19.611 & -0.446 & 6.278 & -0.255 & 1.451 & -0.338 & 3.785 & -0.630 & 3.284 \\
\hline
\end{tabular}


TABLE 4. EFFECTS EXPIRATION ON THE VOLUME OF THE INDEXES

\begin{tabular}{|c|c|c|c|c|c|c|}
\hline & IBEX35 & IbexCOM & IbexFIN & IbexUTI & IbexIND & IbexNM \\
\hline$\beta_{0}$ & $\begin{array}{c}21.204 \\
(1347.50)\end{array}$ & $\begin{array}{c}17.607 \\
(513.58)\end{array}$ & $\begin{array}{c}19.859 \\
(753.24)\end{array}$ & $\begin{array}{c}20.470 \\
(1148.83)\end{array}$ & $\begin{array}{c}19.488 \\
(931.38)\end{array}$ & $\begin{array}{c}18.568 \\
(505.15)\end{array}$ \\
\hline$\beta_{2}$ & $\begin{array}{l}-0.206 \\
(-5.87)\end{array}$ & & $\begin{array}{l}-0.199 \\
(-3.39)\end{array}$ & $\begin{array}{l}-0.241 \\
(-6.07)\end{array}$ & $\begin{array}{l}-0.156 \\
(-3.35)\end{array}$ & $\begin{array}{l}-0.180 \\
(-2.20)\end{array}$ \\
\hline$\beta_{4}$ & & $\begin{array}{l}0.148 \\
(1.91)\end{array}$ & & & & \\
\hline$\delta_{0}$ & $\begin{array}{l}0.284 \\
(4.73)\end{array}$ & $\begin{array}{l}0.062 \\
(0.43)\end{array}$ & $\begin{array}{l}0.417 \\
(4.15)\end{array}$ & $\begin{array}{l}0.253 \\
(3.72)\end{array}$ & $\begin{array}{l}0.230 \\
(2.89)\end{array}$ & $\begin{array}{l}0.128 \\
(0.91)\end{array}$ \\
\hline$\delta_{-1}$ & $\begin{array}{l}0.062 \\
(1.03)\end{array}$ & $\begin{array}{c}-0.040 \\
(-0.31) \\
\end{array}$ & $\begin{array}{l}0.012 \\
(0.12)\end{array}$ & $\begin{array}{l}0.036 \\
(0.53)\end{array}$ & $\begin{array}{l}0.122 \\
(1.53)\end{array}$ & $\begin{array}{l}0.077 \\
(0.55)\end{array}$ \\
\hline$\delta_{-2}$ & $\begin{array}{l}0.119 \\
(1.99) \\
\end{array}$ & $\begin{array}{c}0.193 \\
(1.486) \\
\end{array}$ & $\begin{array}{c}0.118 \\
(1.175) \\
\end{array}$ & $\begin{array}{l}0.136 \\
(2.00) \\
\end{array}$ & $\begin{array}{l}0.084 \\
(1.06) \\
\end{array}$ & $\begin{array}{l}0.081 \\
(0.57) \\
\end{array}$ \\
\hline$\delta_{+1}$ & $\begin{array}{l}0.293 \\
(4.53)\end{array}$ & $\begin{array}{c}0.153 \\
(1.178)\end{array}$ & $\begin{array}{l}0.429 \\
(3.95)\end{array}$ & $\begin{array}{l}0.285 \\
(3.89)\end{array}$ & $\begin{array}{l}0.130 \\
(1.52)\end{array}$ & $\begin{array}{l}0.095 \\
(0.62)\end{array}$ \\
\hline Log.Ver. & -36.92 & -369.75 & -259.35 & -90.49 & -159.74 & $\begin{array}{l}-402.59 \\
\end{array}$ \\
\hline SIC & -2.58 & -1.03 & -1.54 & -2.33 & -2.01 & -0.88 \\
\hline AIC & -2.63 & -1.09 & -1.60 & -2.39 & -2.06 & -0.94 \\
\hline
\end{tabular}

Notes: (i) Estimates OLS. Among parenthesis the t-ratio is presented, robust to heteroskedasticity and autocorrelation (Newey-West (1987)) (ii) AIC is the Approach of Akaike and SIC the Approach of information of Schwarz.

TABLE 5. EXPIRATION EFFECTS ON THE STOCK PRICES OF THE INDEXES

\begin{tabular}{|c|c|c|c|c|c|c|}
\hline & IBEX35 & IbexCOM & IbexFIN & IbexUTI & IbexIND & IbexNM \\
\hline$\beta_{0}$ & $\begin{array}{l}0.019 \\
(0.19)\end{array}$ & $\begin{array}{l}0.036 \\
(0.67)\end{array}$ & $\begin{array}{l}0.244 \\
(1.86)\end{array}$ & $\begin{array}{l}0.001 \\
(0.01)\end{array}$ & $\begin{array}{l}0.002 \\
(0.04)\end{array}$ & $\begin{array}{l}-0.252 \\
(0.11)\end{array}$ \\
\hline$\beta_{3}$ & & $\begin{array}{l}-0.215 \\
(-1.76)\end{array}$ & $\begin{array}{l}-0.607 \\
(-2.29)\end{array}$ & & & \\
\hline$\beta_{4}$ & $\begin{array}{l}-0.103 \\
(-0.46) \\
\end{array}$ & & $\begin{array}{l}-0.423 \\
(-1.57) \\
\end{array}$ & & & \\
\hline$\delta_{0}$ & $\begin{array}{l}-1.118 \\
(-2.75)\end{array}$ & $\begin{array}{l}-0.291 \\
(-1.41)\end{array}$ & $\begin{array}{l}-1.131 \\
(-2.36)\end{array}$ & $\begin{array}{l}-1.166 \\
(-2.82)\end{array}$ & $\begin{array}{l}-0.579 \\
(-2.42)\end{array}$ & $\begin{array}{l}-1.559 \\
(-2.29)\end{array}$ \\
\hline$\delta_{-1}$ & $\begin{array}{l}-0.049 \\
(-0.13)\end{array}$ & $\begin{array}{l}-0.282 \\
(-1.36)\end{array}$ & $\begin{array}{l}-0.123 \\
(-0.28)\end{array}$ & $\begin{array}{l}0.052 \\
(0.12)\end{array}$ & $\begin{array}{l}-0.430 \\
(-1.79)\end{array}$ & $\begin{array}{l}0.128 \\
(0.18)\end{array}$ \\
\hline$\delta_{-2}$ & $\begin{array}{c}-0.118 \\
(-0.31) \\
\end{array}$ & $\begin{array}{l}0.252 \\
(1.12)\end{array}$ & $\begin{array}{l}0.160 \\
(0.33)\end{array}$ & $\begin{array}{l}-0.027 \\
(-0.06)\end{array}$ & $\begin{array}{l}-0.143 \\
(-0.60)\end{array}$ & $\begin{array}{l}0.402 \\
(0.59)\end{array}$ \\
\hline$\delta_{+1}$ & $\begin{array}{l}-0.282 \\
(-0.75)\end{array}$ & $\begin{array}{l}-0.240 \\
(-1.16)\end{array}$ & $\begin{array}{c}-0.378 \\
(-0.856)\end{array}$ & $\begin{array}{l}-0.570 \\
(-1.38)\end{array}$ & $\begin{array}{l}0.171 \\
(0.71)\end{array}$ & $\begin{array}{l}-0.098 \\
(-0.14)\end{array}$ \\
\hline Log.Ver. & -821.33 & -568.89 & -890.01 & -869.74 & -634.68 & -1082.64 \\
\hline SIC & 1.06 & -0.10 & 1.40 & 1.27 & 0.18 & 2.26 \\
\hline AIC & 1.01 & -0.16 & 1.33 & 1.23 & 0.13 & 2.22 \\
\hline $\begin{array}{l}\mathrm{Q}(10) \\
\mathrm{p} \text {-value }\end{array}$ & $\begin{array}{c}9.796 \\
(0.458)\end{array}$ & $\begin{array}{l}25.915 \\
(0.004)\end{array}$ & $\begin{array}{l}11.187 \\
(0.343)\end{array}$ & $\begin{array}{c}8.857 \\
(0.546)\end{array}$ & $\begin{array}{l}14.093 \\
(0.169)\end{array}$ & $\begin{array}{l}13.796 \\
(0.183)\end{array}$ \\
\hline $\begin{array}{l}\mathrm{Q}(20) \\
\mathrm{p} \text {-value }\end{array}$ & $\begin{array}{l}31.227 \\
(0.070)\end{array}$ & $\begin{array}{l}36.553 \\
(0.013)\end{array}$ & $\begin{array}{l}32.902 \\
(0.035)\end{array}$ & $\begin{array}{l}24.152 \\
(0.236)\end{array}$ & $\begin{array}{l}33.853 \\
(0.027)\end{array}$ & $\begin{array}{l}25.905 \\
(0.169)\end{array}$ \\
\hline $\begin{array}{l}\mathrm{Q}^{2}(10) \\
\mathrm{p} \text {-value }\end{array}$ & $\begin{array}{l}88.410 \\
(0.000) \\
\end{array}$ & $\begin{array}{l}80.171 \\
(0.000) \\
\end{array}$ & $\begin{array}{l}137.06 \\
(0.000) \\
\end{array}$ & $\begin{array}{l}17.460 \\
(0.065) \\
\end{array}$ & $\begin{array}{l}148.02 \\
(0.000)\end{array}$ & $\begin{array}{l}39.313 \\
(0.000) \\
\end{array}$ \\
\hline $\begin{array}{l}Q^{2}(20) \\
p \text {-value }\end{array}$ & $\begin{array}{l}113.44 \\
(0.000)\end{array}$ & $\begin{array}{l}82.995 \\
(0.000)\end{array}$ & $\begin{array}{l}172.47 \\
(0.000)\end{array}$ & $\begin{array}{l}29.013 \\
(0.088)\end{array}$ & $\begin{array}{l}168.95 \\
(0.000)\end{array}$ & $\begin{array}{l}46.103 \\
(0.001)\end{array}$ \\
\hline $\begin{array}{c}\text { Engle } \\
\text { (p-value) }\end{array}$ & $\begin{array}{c}5.17 \\
-(0.00)\end{array}$ & $\begin{array}{c}6.56 \\
(0.00)\end{array}$ & $\begin{array}{l}30.81 \\
(0.00)\end{array}$ & $\begin{array}{l}12.12 \\
(0.00)\end{array}$ & $\begin{array}{l}11.40 \\
(0.00)\end{array}$ & $\begin{array}{c}3.42 \\
(0.00)\end{array}$ \\
\hline
\end{tabular}

Notes: (i) Estimates OLS. Among parenthesis the t-ratio is presented, robust to heteroskedasticity and autocorrelation (Newey-West (1987)) (ii) AIC is the Approach of Akaike and SIC the Approach of information of Schwarz. 
(iii) $\mathrm{Q}(\mathrm{k})$ it denotes the statistical of Box-Ljung to contrast the null hypothesis of incorrelación until of order $\mathrm{k}$ in the series and Q2(k) it denotes the same one statistical for series of the squares. Among parenthesis the corresponding p-value is represented, based on the approach $\chi_{\mathrm{k}}^{2}$ to the distribution of the statistical one of Box-Ljung.

(iv) The Engle test [1982] comes given by $h_{t}=\lambda_{0}+\lambda_{1} \varepsilon_{\mathrm{t}-1}^{2}$. Under the null hypothesis of homoskedasticity $\left(\lambda_{1}=0\right)$ the statistical $T R^{2}$ is distributed like a distribution $\chi^{2}(1)$, being $\mathrm{T}$ the size muestral and $\mathrm{R}^{2}$ the correlation coefficient to the square.

TABLE 6. EXPIRATION EFFECTS ON THE CONDITIONAL VARIANCE OF THE INDEXES

\begin{tabular}{|c|c|c|c|c|c|c|}
\hline & IBEX35 & IbexCOM & IbexFIN & IbexUTI & IbexIND & IbexNM \\
\hline$\alpha_{0}$ & $\begin{array}{l}0.087 \\
(1.16)\end{array}$ & $\begin{array}{l}0.025 \\
(2.98) \\
\end{array}$ & $\begin{array}{l}0.056 \\
(1.32) \\
\end{array}$ & $\begin{array}{l}0.488 \\
(1.11) \\
\end{array}$ & $\begin{array}{l}0.058 \\
(2.60) \\
\end{array}$ & $\begin{array}{l}0.588 \\
(3.28) \\
\end{array}$ \\
\hline$\alpha_{1}$ & $\begin{array}{l}0.006 \\
(0.15) \\
\end{array}$ & $\begin{array}{l}0.027 \\
(1.18)\end{array}$ & $\begin{array}{l}0.027 \\
(0.90) \\
\end{array}$ & $\begin{array}{l}0.093 \\
(1.80) \\
\end{array}$ & $\begin{array}{l}0.012 \\
(0.40) \\
\end{array}$ & $\begin{array}{l}0.038 \\
(1.12) \\
\end{array}$ \\
\hline$\alpha_{2}$ & $\begin{array}{c}0.888 \\
(16.69)\end{array}$ & $\begin{array}{c}0.830 \\
(42.26)\end{array}$ & $\begin{array}{c}0.906 \\
(31.70)\end{array}$ & $\begin{array}{l}0.754 \\
(4.87)\end{array}$ & $\begin{array}{c}0.903 \\
(23.11)\end{array}$ & $\begin{array}{c}0.863 \\
(20.47)\end{array}$ \\
\hline$\alpha_{3}$ & $\begin{array}{l}0.147 \\
(2.87) \\
\end{array}$ & $\begin{array}{l}0.286 \\
(7.87)\end{array}$ & $\begin{array}{l}0.186 \\
(4.17) \\
\end{array}$ & & $\begin{array}{l}0.088 \\
(3.11) \\
\end{array}$ & $\begin{array}{l}0.101 \\
(2.63)\end{array}$ \\
\hline$\delta_{0}$ & $\begin{array}{l}0.353 \\
(0.27) \\
\end{array}$ & $\begin{array}{l}0.069 \\
(0.58) \\
\end{array}$ & $\begin{array}{l}1.400 \\
(0.90)\end{array}$ & $\begin{array}{l}0.047 \\
(0.03) \\
\end{array}$ & $\begin{array}{l}0.605 \\
(1.05)\end{array}$ & $\begin{array}{l}-2.262 \\
(-0.84) \\
\end{array}$ \\
\hline$\delta_{-1}$ & $\begin{array}{l}-1.020 \\
(-0.75) \\
\end{array}$ & $\begin{array}{l}-0.174 \\
(-1.45) \\
\end{array}$ & $\begin{array}{l}-0.474 \\
(-0.42) \\
\end{array}$ & $\begin{array}{l}-1.269 \\
(-0.71) \\
\end{array}$ & $\begin{array}{l}-0.352 \\
(-0.87) \\
\end{array}$ & $\begin{array}{l}0.580 \\
(0.18) \\
\end{array}$ \\
\hline$\delta_{-2}$ & $\begin{array}{c}1.08 \\
(0.82) \\
\end{array}$ & $\begin{array}{l}-0.008 \\
(-0.07) \\
\end{array}$ & $\begin{array}{l}0.401 \\
(0.34) \\
\end{array}$ & $\begin{array}{l}1.736 \\
(0.95) \\
\end{array}$ & $\begin{array}{l}-0.074 \\
(-0.20) \\
\end{array}$ & $\begin{array}{l}-2.425 \\
(-0.96) \\
\end{array}$ \\
\hline$\delta_{+1}$ & $\begin{array}{l}-0.228 \\
(-0.21) \\
\end{array}$ & \begin{tabular}{|l|}
-0.132 \\
$(-1.51)$ \\
\end{tabular} & $\begin{array}{l}-0.834 \\
(-0.59) \\
\end{array}$ & $\begin{array}{l}0.243 \\
(0.21)\end{array}$ & $\begin{array}{l}-0.641 \\
(-1.32)\end{array}$ & $\begin{array}{c}-0.684 \\
(-0.419)\end{array}$ \\
\hline Log.Ver. & 1180.73 & -497.16 & -845.01 & -870.35 & -602.01 & -1063.77 \\
\hline SIC & 1.12 & -0.06 & 1.45 & 1.33 & 0.25 & 2.33 \\
\hline AIC & 1.04 & -0.13 & 1.37 & 1.26 & 0.17 & 2.25 \\
\hline
\end{tabular}

Notes: (i) Results using the GJR(1,1) model, except for the conditioned variance of the return of the index dear IbexUTI with GARCH(1,1). Among parenthesis they figure the t-ratio.

(ii) AIC is the Approach of Akaike and SIC the Approach of information of Schwarz.

\section{References}

1. ANDRÉS, A. (2001). "Impacto sobre el mercado bursátil del vencimiento de los contratos de derivados sobre el Ibex 35", Investigaciones Económicas, XXV (1), 203-234.

2. BLANCO, R. (1998). "Efectos sobre la volatilidad del mercado bursátil de la introducción de los contratos de futuros y opciones so bre el índice Ibex 35", mimeo.

3. BOLlERSLEV, T. (1986). "Generalized Autoregressive Conditional Heteroskedasticity", Journal of Econometrics. 31, 307-327.

4. BOLLERSLEV, T., ENGLE, R.F and NELSON, D.B. (1994). "ARCH models". Handbook of Econometrics, IV, R.F. Engle and D.L. McFadden (eds.), Amsterdam, North Holland.

5. BROWN, F., J. FELL and S. HUGHES (1994). "Derivatives; their contribution to markets and supervisory concerns", Quarterly Bulletin Bank of Ireland, 37-70.

6. CINAR, E. and J. VU (1987). "Evidence on the effect of option expiration of stock prices", Financial Analyst Journal, 43, 55-57.

7. CHRISTIE, A.A. (1982) "The stochastic behaviour of common stock variances: valued leverage and interest effects". Journal of Financial Economics. 10, 407-432.

8. Comisión Nacional del Mercado de Valores, Informe Anual, different numbers, Madrid.

9. CORREDOR, LECHÓN and SANTAMARÍA (1997). "El vencimiento de los derivados y el Ibex-35, Revista de Economía Aplicada 5, 81-97.

10. ENGLE, R.F. (1982)."Autorregressive Conditional Heteroskedasticity with Estimates of the Variance of United Kingdom Inflation". Econometrica, 50, 987-1008.

11. GLOSTEN, L.R., JAGANATHAN, R. and RUNKLE, D. [1993]. "On the relationships between the expected value and the volatility of the nomna excess return on stocks", Journal of Finance, 48,1779-1801.

12. GROSSMAN, S. (1988). "An analysis of the implications for stock and futures price volatility of program trading and dynamic hedging strategies", Journal of Business 61, 275-298.

13. LEÓN, A. and J. MORA (1996). "Modelling conditional heteroskedasticity: application to stock return index Ibex35”, WP-Ad-96-11, Instituto Valenciano de Investigaciones Económicas.

14. MACKINNON, J.G. (1991). "Critical values for cointegration test" in R.F. Engle and C.W.J. Granger (eds): Longrun economic relationships: Readings in cointegration, Oxford: Oxford University Press, 267-276. 
15. NELSON, D.B. (1991). "Conditional Heteroscedasticity in Asset Returns: A New Approach". Econometric, 59, 347-370.

16. NEWEY, W. and K. WEST (1987). "A simple positive semi-definite, heteroskedasticity and autocorrelation consistent covariance matrix", Econometrica 55, 703-708.

17. PARDO, A. (1998). "Efectos de los mercados derivados sobre el Ibex-35 en el activo subyacente", Revista Española de Financiación y Contabilidad 28, 99-128.

18. RYSTROM, D. Y E. BENSON (1989). "Investor psychology and the day-of-the-week effect", Financial Analyst Journal 45, 75-78.

19. Sociedad de Bolsas (1996-2001). "Informes mensules", Madrid.

20. STOLL, H. Y W. WHALEY (1987). "Program trading and expiration-day effects", Financial Analysts Journal 43, 16-28.

21. TAUCHEN, G., H. ZHANG Y H. LIU (1996). "Volume, volatility and leverage: A dynamic analysis", Journal of Econometrics 74, 177-208.

Notes 
Notes 